\title{
"THE RETURNING ECHOES OF OUR MEMORY" Networks of Memory and Postcolonial Trauma in Tan Twan Eng's The Gift of Rain
}

\author{
Vandana Saxena \\ Taylor's University Malaysia \\ Vandana.Saxena@taylors.edu.my
}

\begin{abstract}
In the societies forged at the anvil of colonial violence, the stories of the past are a contested territory. For postcolonial writers, literature offers a space to explore the trauma that marks the colonial experience and also to forge connections based on common suffering and loss. Stories and experience, when shared, produce new social relations and understanding to replace the relationships and legacies of the past. This paper explores Tan Twan Eng's novel, The Gift of Rain, to trace the interlinked legacies of the Second World War and colonialism in Malaysia. As Tan's characters-all from varied cultural and national backgrounds-meet, the cross-cultural storytelling creates a network of memories that transcend the boundaries of nationality, culture, and ethnicity. Trauma acquires a transnational and transhistorical dimension which enables the protagonists to live and engage with the colonial legacy.
\end{abstract}

\section{Keywords}

Malaysian literature; networks of memory; postcolonial fiction; trauma

\section{About the Author}

Dr. Vandana Saxena teaches English at the School of Liberal Arts and Sciences, Taylor's University, Malaysia. Her major research interests are South and Southeast Asian literature, Memory Studies, Postcolonial theory, and creative writing. These interests are reflected in her numerous publications and presentations. Her book, The Subversive Harry Potter, is one of the seminal literary studies on J.K. Rowling's immensely popular Harry Potter series and Young Adult fantasy fiction. Besides academia, Dr. Saxena is a prolific writer and has published her fiction online. 
Are all of us the same, I wonder, navigating our lives by interpreting the silences between words spoken, analyzing the returning echoes of our memory in order to chart the terrain, in order to make sense of the world around us? (Tan, The Garden of Evening Mist 322).

Tan Twan Eng's The Gift of Rain begins with Philip Hutton, a half-Chinese and half-English, old man, living out his days in Penang-a place full of memories of his childhood and the Second World War. Despite his preoccupation with the past, Philip's memories are shrouded in silence. For nearly fifty years, he has neither shared those memories nor talked about the past. This silence is broken when he meets Michiko, the past lover of Hayato Endo, a Japanese diplomat with whom Philip had shared an intense relationship during the War years. Told in retrospect, the novel is an account of the relationship between Philip and Endo, and the intricate manner in which it is tangled with the histories of their respective nations. The Japanese occupation of Malaya, the violence perpetrated on the Chinese community, and the gradual decline of British influence - all these shape Philip's actions and choices during the War. In the course of the novel, Philip's story invokes Michiko's own memories of the suffering in a small Japanese village during the War. The experiences, though essentially different, enable them to forge a bond of empathy and understanding or what Stef Craps in Postcolonial Witnessing calls cross-traumatic affiliation: "a way of bringing different historical traumas into contact in an ethically responsible manner; that is, without collapsing them into one another, preserving the distance between them" (17). Instead of a traumatized silence, cross-traumatic affiliations create a bond of compassion and solidarity. While the traumatic memories remain individual and specific, the experience of trauma is neither unique nor incomprehensible (as early Trauma Studies would insist). Storytelling in Tan's novel becomes a means to bear witness to the historical traumas and the efforts to keep the memories alive in the present. Sharing memories has the potential to create spaces for understanding, identification and also for addressing the socio-political contexts of trauma. Trauma, in such shared space, becomes a part of the process - an outcome of ongoing cultural and political practices as well as a space for intervention where different traumatic stories when told and shared produce new social relations and understanding to replace the legacies of the past. The postcolonial condition is marked by the persistence or survival with trauma rather than the narratives of healing and recovery.

A contemporary Malaysian novelist whose novels have gained wide critical acclaim, Tan Twan Eng frequently returns to the colonial violence in Malaya during the Second World War. 
[T] he Japanese Occupation was the most catastrophic thing to have happened in Malaysian history. It's a thick demarcation, severing the past from the future; it marked the end of the British colonial empire and the beginning of self-rule. It showed the people that the Western powers were not invincible. After the war, the colonies demanded, and in some cases, fought for independence. It was a period of great change and upheaval, but I was more interested in exploring how ordinary men and women go through their day-to-day lives, how they cope with remembering and forgetting. (Tan, "I Have No Alternative")

In Tan's two novels-The Gift of Rain and The Garden of Evening Mists-the years of Japanese imperialism reveal the messy intersections of race, ethnicity, and violence that lay at the heart of Malaya. The narratives of trauma and violence, filtered through individual memory and subject to the vagaries of remembering and forgetting, offer a multilayered and multidimensional account of the past. The postcolonial condition in Tan's novels is marked by the diverse, distant and yet entangled memories of trauma and suffering. As different protagonists meet and interact, each account of colonial and historical violence emerges in the form of stories that invoke several other. The historical distinction between the colonizer and the colonized, the victim and the perpetrator, is often blurred. This paper explores Tan's novel The Gift of Rain to trace the interlinked legacies of the Second World War and colonialism in Malaysia. As Tan's characters-all from varied cultural and national backgrounds-meet, a cross-cultural network of stories and memories come into being that transcends the boundaries of nationality, culture, and ethnicity. Trauma acquires a transnational and transhistorical dimension, and it is only through cross-cultural sharing of experiences that the protagonists are able to live and engage with the past. The paper begins with an overview of the theories of memory, trauma, and loss, as well as their networked nature in the postcolonial world. The subsequent discussion of the role of literary texts as "portable monuments" focuses on Malaysian English novel as a commemorative genre that bears the memories of history into the present. It highlights the intensely political and social nature of memory and trauma that Malaysian English novels, especially The Gift of Rain, reveal. In the close analysis of the novel that follows, the paper argues that the postcolonial condition is marked by a shift from healing to survival that is enabled by multidirectional sharing of memories. The possibility of recuperation of colonial trauma in postcolonial societies is fraught with tension since the relations to the past are strictly not only to one's own past but also to social and historical formations. Hence postcolonial texts like The Gift of Rain foreground a non-therapeutic relation to colonial trauma "structured around the notion of survival or living on rather than recovery" (Lloyd 212). 


\section{CROSS-TRAUMATIC AFFILIATIONS AND NETWORKS OF MEMORY}

In Unclaimed Experience, a seminal text in the field of Trauma Studies, Cathy Caruth observes that "history, like trauma, is never simply one's own .... history is precisely the way we are implicated in each other's traumas" (24). Despite the centrality of the personal and the individual in the case of memory and trauma, the two fields of study are intensely political. The unspeakable and psychically unassimilable event that forms the core of the traumatic experience makes linear or conventional history impossible: Caruth insists that "[if] PTSD must be understood as a psychological symptom of the unconscious, it is a symptom of history. The traumatized, we might say, carry an impossible history within them, or they become themselves the symptom of a history they cannot entirely possess" (Trauma 5).

So, the impossibility of its representation in language and narrative configures trauma as the silenced engine of history. Since the traumatized are unable to testify in a coherent manner, the traumatic history can be understood peripherally through the observation of delayed responses and "other intrusive phenomena" (Caruth, Unclaimed Experience 11).

However, the recent trend of decolonizing Trauma Studies has challenged the insistence on the unspeakability and the unique nature of the traumatogenic experiences in order to place trauma and memory in specific historical and political contexts. Scholars like Stef Craps, Sam Durrant, and Irene Visser have critiqued Trauma Studies for its focus on event-based Euro-American centric model, calling for a deeper engagement with the cultural inflections that produce and disseminate trauma, for instance, the configurations of the colonial trauma where the systemic nature of power and exploitation makes trauma a collective malady.

Situating trauma in the discourse of historical specificity, Dominick LaCapra in his essay, "Trauma, Absence, Loss," makes a crucial distinction between absence and loss. Losses, he insists "are specific and involve particular events, such as the death of loved ones on a personal level or, on a broader scale, the losses brought about by apartheid or by Holocaust." An absence, on the other hand, "is the absence of an absolute," at a transhistorical and foundational level. This distinction is essential to avoid indiscriminate generalization of historical trauma into the idea of wound culture" (722). In other words, trauma, instead of being a manifestation of an absence of some essentialist absolute, is rooted in a historical context; it is a product of political and cultural formations. This historical turn creates a possibility for socio-political engagement that has the potential to address the condition of loss. For instance, once the trauma and loss under colonial regime are 
contextualized and understood as a manifestation of oppressive politics and power equations, the conditions of colonialism can be addressed.

Hence the historical turn in Trauma Studies has led the scholars to focus on the trauma affected by political power formations like the apartheid or the colonial regimes. Any traumatizing event, Rothberg points out in the Preface to The Future of Trauma Theory, "takes place on the site of-and thoroughly embedded within-a system of violence that is neither sudden nor accidental" (xiv). An individual's experience of pain, loss, and suffering is a part of the collective trauma rooted in the political and cultural fabric which makes trauma a collective malady. While the contexts may vary, the experiences of trauma often overlap. The field widens as Trauma Studies move beyond the Holocaust-centric model to acknowledge the traumas of colonialism, slavery, and other forms of violence.

Connections forged between the traumatized from different sites of suffering not only engage with the political and cultural dimensions of trauma but also enable a network of memories where victims of trauma can share experiences and empathize as they preserve their radical differences. In Writing History, Writing Trauma, LaCapra refers to the notion of empathic unsettlement which "involves a kind of virtual experience which one puts oneself in the other's position while recognizing the difference of that position and hence not taking the other's place" (78).

Thus, instead of the insistence on the unique nature of the traumatic event, empathic yet differential sharing of traumatic memories illuminates what Michael Rothberg calls the "multidirectional" orientation of collective memory. Multidirectional memory is "subject to ongoing negotiation, cross-referencing, and borrowing; as productive and not privative" (Multidirectional Memory 3); it "draw[s] attention to the dynamic transfers that take place between diverse places and times during the act of remembrance" (Multidirectional Memory 11). In other words, multidirectional memory creates a condition for cross-traumatic affiliations between two or more individuals or cultures who have experienced trauma in different ways. Craps insists on this overlap between the fields of Trauma and Postcolonial studies to "bridge a disciplinary divide between Jewish and postcolonial studies preventing the Holocaust and histories of slavery and colonial domination from being considered in a common frame" (Postcolonial Witnessing 73). Hence multidirectional memories and cross-traumatic affiliations enable solidarity without nullifying the uniqueness of individual memory and suffering. The notion of enduring, unknowable, and inexpressible nature of trauma is replaced by aspects of collectivity and interconnectedness that capture the multilayered, multi-sited, and multidirectional dynamics of remembering and forgetting. 
At the same time, an engagement with the historical specificity of trauma facilitates intervention at the political and cultural level. Calling on the category of postcolonial historical novels, Hamish Dalley insists that their origin lies in "places where memories of past violence fissure the imagined community, and, as such, become subject to contestation" (10). Insisting on a rapprochement between Postcolonial and Trauma Studies, Craps and Buelens underline the ethical commitment of postcolonial literature "to make visible the creative and political" rather than the "pathological and negative" (127). Reflecting on the current theoretical positions, psychical trauma needs to be understood as a product of historical and political formations. The experience of trauma is located in a network of memories where sites of suffering differ but the experience when shared has the potential to generate empathy, solidarity, and also a heightened understanding of cultural formations behind trauma and loss. The postcolonial condition entails survival with this trauma as well as the awareness of its socio-cultural aspects.

\section{PORTABLE MEMORIES AND MALAYSIAN POSTCOLONIAL FICTION}

The start of the millennium has witnessed a surge in the prominence and popularity of Malaysian novels in English. Most of the authors-Tan Twan Eng, Tash Aw, Rani Manicka, Preeta Samasaran and others-live out of Malaysia. Even as they target a global audience, their fictions are deeply embedded in the memories and narratives of the ethnic minorities of Malaysia. Tan's novels and Aw's The Harmony Silk Factory turn to the Chinese community of Malaysia while Manicka's The Rice Mother focuses on the travails of the immigrants from Sri Lanka. Samasaran's Evening is the Whole Day tells the story of an immigrant Indian girl in Malaysia. Angela Poon, in her study of Tan's fiction, insists on the transcultural and transnational frame of reference when approaching Malaysian English fiction, given its publication and circulation in the international market. Philip Holden has also suggested that since the current crop of Malaysian novels carries currency and meaning in the global as well as the local context, it is increasingly transnational in content.

More significant for this study is the transhistorical aspect of Malaysian literature in English. Contemporary Malaysian Literature in English, like the novels mentioned above, reach out to the readers who are distant in terms of time and place. The juxtaposition of the past and the present becomes a means of reflecting on the historical consciousness in a society where the inequalities and dilemmas of the present are rendered explicit by mediations on the traumatic legacies of the past. In family sagas like The Rice Mother and The Harmony Silk Factory, the families, as well as their failures and traumas, become a means to critique the historical trajectory of the Malaysian nation and its emergence from the sites of colonial 
trauma. The postcolonial nation, carrying the legacy of the colonialism and the war that created it, brings the horrors of the past into the present in the form of racial and ethnic divisions. These racial tensions are compulsively repeated in independent Malaysia through the exclusionary conflicts like the race riots of 1969, where the loss is re-lived "through the actual return of the trauma, and through its inadvertent repetition, or transmission, from one generation to another" (Felman and Laub 66). The collective memories of the past trauma shape the current racial dilemmas in contemporary Malaysia where race is "a palpable, visible, heritable inevitability that overdetermines one's identity, loyalties, morality and religion" (Lim, "Introduction" 1).

In literature, this grid of racial and ethnic tension in the country is portrayed through the intersection of the significant moments in the national history. The Gift of Rain is set in the 1990s, fifty years after the events of the Japanese Occupation of Malaya (1941-1945). The novel also evokes the distant memories of the disintegration of the Chinese royal family and the migration of the Chinese to Malaya in the late nineteenth century, the arrival of the British, and the racial politics that created the contours of later racial tension in the region. In its vacillation between the memories of the past and the consciousness of the present, the narrative explores the alienation and disconnectedness that Philip experiences due to the colonial power structure of pre-independence Malaya. As a colonial subject, Philip Khoo-Hutton occupies a peculiar though not unique position in colonial Penang. According to the 1931 census, there were 17,0oo Eurasians in Penang (Augustin). They were rendered particularly vulnerable by the British withdrawal from Malaya during the Second World War. As Philip rediscovers his Chinese ancestry and forms relationships within the community, he becomes more susceptible to trauma. The Chinese community of Malaya was at the center of conflict during the Second World War and the Japanese Occupation - as the main victims of violence and also as the prime movers of the forces of resistance like the Malaysian People's Anti-Japanese Army (MPAJA). Later, during the events of the Emergency and the 1969 riots, the community has been at the center of the nation's history and politics, especially its traumatic moments.

Thus as a postcolonial text preoccupied with the trauma of colonial violence and racial conflict, Tan's novel is concerned with the lost histories that have been marginalized by the grand narratives of colonialism and nationalism. They constitute what Ann Rigney calls "portable monuments" that are "susceptible to being relocated ... because they are fictional and as such not bound to any single historical context. Reactivated at a later point in time through the medium of such texts, memories can enter into new combinations" (383). The portability of literary texts encourages transcultural reflections on the specific local history, in this case, the stories of migration, alienation, and racial and ethnic violence 
in wartime Malaya. At the same time, the transnational circulation of the novels situates the local in the global: the Malaysian novels co-exist with other stories of exile, migration, and suffering around the world, in the past and present. As Astrid Erll insists, such transculturalism offers a perspective that transcends the national borders: that is "directed towards mnemomic process unfolding across and beyond cultures" (9). Malaysian novels in English are transhistorical narratives encouraging juxtaposition of the past against the present, of personal memory against the collective memories, and the local against the global. In Tan's novels, as characters of different nationalities and ethnicities meet and interact, the divisions of history are constantly reconstituted. At a time when the generation of Second World War survivors is rapidly disappearing, such cross-cultural storytelling in the literary and cultural sphere is essential to preserve and also to "create" memories for the generations who have not witnessed the horror of the Second World War.

\section{STORIES OF SUFFERING}

Tan's The Gift of Rain operates in the zone of memory that is crisscrossed by the accounts across time and place. At its center is Philip Khoo-Hutton, part-English, part-Chinese who, even after fifty years of the War, is reviled and revered equally by different segments of Penang society for the role he played during the Japanese Occupation of Malaya. While some people of Penang see him as a savior who managed to rescue many of their family and friends from the Japanese killing squads, for the others he is a traitor who betrayed the people of Penang by collaborating with the Japanese. Living under the shadow of mistrust, Philip has neither offered any explanations nor sought to justify his role as a double agent during the War years. He cuts a lonely figure, living alone in his father's house after the death of his family. He has had no close relationships or friendships in the post-war years.

This isolation is interrupted by the arrival of Michiko Murakami, an ailing and elderly Japanese woman. Michiko brings the tokens of the past that led her to the journey to Penang: a letter from Endo, a Japanese diplomat posted in Malaya during the War years, and Endo's Nagamitsu sword which was part of a pair, the other being owned by Philip. For Philip, the re-appearance of Nagamitsu sword was cutting a gash in the dyke he built to house his memories and emotions (Tan, The Gift of Rain 27).

The moment I had been waiting for. Fifty years I had waited to tell my tale, as long as the time Endo-san's letter took to reach Michiko. Still I hesitated like a penitent sinner facing my confessor, unsure if I wanted another person to know my many shames, my failures, my unforgivable sins. (Tan, The Gift of Rain 35)

Kritika Kultura 33/34 (2019/2020): 187-197

(C) Ateneo de Manila University

<http://journals.ateneo.edu/ojs/kk/> 
Philip's silence is compounded by his guilt of the death of family and friends and his own survival during the War. As Philip hesitates to tell about his "shames, failures and unforgivable sins," one realizes that though he has never talked about it, the unspoken past preoccupies Philip.

Thus the act of telling the story is an act of exposing the self. It requires a listener to witness the testimony. So Michicko's role is not only that of a catalyst initiating Philip's story; she is crucial to the narrative as a witness to the testimony. In the dialogic space between the victim and the listener, history interacts with the present, and the memories are reclaimed by finding links with the present. Felman and Laub claims that in a testimony of the past, the listener is a participant who stands at a critical distance away from the victim. Yet her presence enables the narration of trauma: “The listener has to feel the victim's victories, defeats and silences, know them from within, so that they can assume the form of testimony" (58).

Hence the novel is structured in terms of a frame narrative in which Michiko plays the role of a witness with whom Philip, the victim, shares his trauma. Yet the two preserve their radical otherness:

The listener, however, is also a separate human being and will experience hazards and struggles of his own, while carrying out this function of a witness to the trauma. While overlapping, to a degree, with the experience of the victim, he nonetheless does not become the victim-he preserves his own separate place, position and perspective; a battleground for forces raging in himself, to which he has to pay attention and respect if he is properly carrying out his task. (Felman and Laub 58)

Despite her own suffering and her empathy for Philip, Michiko's presence as a listener does not challenge Philip's position as the victim of Japanese atrocities in Malaya; neither does her story usurp the centrality of Philip's narrative in the novel. The purpose that Michiko and her story serve is that of locating Philip's story in a larger narrative of suffering and violence shared by the victims of the War. This is in sharp contrast to the silence and isolation that has marked most of Philip's life.

As the biracial son of Noel Hutton, the owner of a British trading company in Penang, Philip hovers on the peripheries of the different worlds of Britain, Malaya, and China. His mother's early death severed his connection from his Chinese ancestry. Though he lives with his English family, here too he exists on the margins: "Even though half of me is English I have never hungered for England. England is a foreign land, cold and gloomy" (Tan, The Gift of Rain 31).

Though Philip's mixed blood undoes the conventional colonizer-colonized dichotomy, it creates barriers to establishing contact with either. When he meets 
Endo, he is deeply aware of his position as an "other," a foreigner on the margins of the two communities: "How to explain this stranger the sense of not being connected to anything? It struck me at the moment that while other children become orphans when their parents died, my future as an orphan had been cast the night my parents met and fell in love" (Tan, The Gift of Rain 46).

This awareness raises barriers that inhibit all interpersonal connections, especially the intimate ones. It is not a single traumatic event but what Maria Root calls "insidious trauma" which diverges from the event-based model of trauma in underlining the everyday conditions as potential conditions of trauma; it "refers to the traumatogenic effects of oppression that are not necessarily overtly violent or threatening to bodily well-being at the given moment but that do violence to the soul and spirit" (3). In other words, insidious trauma refers to the traumatic effects of long-term or repeated experiences that cause psychological harm, such as living in a colonized condition. Philip's experiences while not inducing any physical unrest constitute an insidious form of trauma that shapes his worldview. Voiced by a young boy, such insidious suffering is dismissed as a childish concern: "When I was younger I had tried to explain this to my father, when the boys at school had taunted me. But he had dismissed my words, and said I was being silly and too sensitive. I knew then that I had no choice but to harden myself against the insults and whispered comments, and to find my own place in the scheme of life" (Tan, The Gift of Rain 40). Encountering ridicule, dismissal, and embarrassment on the part of his siblings at "explaining a half Chinese relations to their English friends and distant relations," Philip lapses into silence (Tan, The Gift of Rain 42). Unlike Michiko who comes as a willing listener, the refusal on the part of the father and the siblings to listen and acknowledge suffering arising from his multiracial ancestry creates gaps and silences within the familial relationship. Despite the intimate nature of these relationships, for Philip, his cross-cultural origins become a barrier in developing interpersonal relationships.

The situation is further complicated by Philip's existence in two worlds which are not equal. While he finds himself alienated from the "English-ness" of the household, the Chinese part of his ancestry remains severed for long as he has little contact with his maternal family. The only link to China during the childhood is Uncle Lim, a servant who would entertain young Philip with wonderful stories of "home." Although he finds them "fascinating" as a child, he soon loses interest: "as I grew older the stories seemed to stagnate and I became tired of them" (Tan, The Gift of Rain 117). The English as colonizers hold power and sway not only over the society of Penang but also over the minds and perceptions of the subject. For Philip, after the death of the mother, his Chinese heritage has never been a subject worth exploring. 
This split in Philip's psyche widens further when subjected to extreme violence during the years of the Japanese Occupation. In 1939, in the absence of his English family, a chance meeting with Hayato Endo, a Japanese consular officer in his late forties, gives a new direction to Philip's life. The two develop an instant bond that grows in intensity as Philip learns and masters the Japanese language, culture, and the martial art form of aikido. When he is cautioned against Endo's nationality and Japanese hostilities against China and England, Philip remains nonchalant, reiterating his alienation with respect to England as well as China: "I felt no connection with China, or with England. I was a child born between two worlds, belonging to neither. From the very beginning, I treated Endo-san not as a Japanese, not as a member of a hated race, but as a man, and that was why we forged an instant bond" (Tan, The Gift of Rain 48-49).

As the story progresses, it becomes clear that Philip's attempt to excise the cultural linkages and establish a relationship with Endo that is based purely on individual attachment is doomed to failure. Though Philip insists that he has discarded his English-Chinese origin, Endo is deeply imbued in the hierarchy of Japanese officialdom bound together with an absolute loyalty to the Japanese Emperor. "If we fail in our duty, we fail our country, and our family," he tells Philip (Tan, The Gift of Rain 10o). In one of the episodes during their journey from Penang to Kuala Lumpur, Endo apprehends and arrests Yasuaki, one of his countrymen who has strayed from duty by forming a romantic attachment with a local woman. When Philip questions the value of such duty, Endo's answer is unequivocal: "it has always been so in our way of life. One cannot escape it" (Tan, The Gift of Rain 101). Thus, though Philip comes to admire Endo, aikido, and certain ways of the Japanese, there are aspects of culture that remains incomprehensible. He remains an outsider, a half-Chinese from Malaya, learning Japanese martial arts, language, and culture. On the other hand, Endo's single-minded focus on duty hints at the limited nature of their friendship.

Thus Philip's alienation is rooted in a specific cultural and historical context: the denial of his biracial identity wherein he can neither be a British nor a Chinese, nor can he identify with the Japanese in entirety. Though the friendship with Endo, as pointed out earlier, carries the seeds of its own failure, the cross-cultural contact makes Philip more receptive to his own heritage. Much later when he meets his Chinese grandfather, the embarrassment and alienation are replaced with a tentative sense of belonging. It is evident in the scene where Philip's grandfather, Mr. Khoo, takes him on a tour to Chinatown, leading him through the streets of Chinese residents who all share the Khoo name. He reads the plaques in the temple that list the names of all the Khoos and their accomplishments. In the course of this scene, Philip learns to identify with his ethnic identity as a half-Chinese. Mr. Khoo shares not only the ethnic and cultural aspects of his Chinese heritage but also the 
stories about his family, of their life in China, and the journey to Malaya. These narratives and patterns of life from which he had been alienated become familiar. As Mr. Khoo shares the story of his life in the Forbidden City and the intrigues in the palace, his narrative situates Philip in a network of relationships constituted by the past and the present-a position that he had been unavailable to him in his English household. As a young boy, while Philip plays the role of the listener or the witness of his grandfather's history, he also imbibes it as part of his own identity. Feint, et al. insist that "acts of remembering correspond to speech acts" (29) which "place every individual interpretation of the past in a social context" (3). Mr. Khoo's storytelling is an act of sharing the past and bequeathing it to his grandson in all its social, cultural, and political complexities. The visit to the Chinatown and the temple is a part of Philip's initiation into the cultural history of the Chinese community in Malaya.

To a large extent, the grandfather manages to animate the silence that marked Philip's life with his English family and give him a unique sense of self: "You are of the two worlds...You have the ability to bring all of life's disparate elements into a cohesive whole" (Tan, The Gift of Rain 234). This acknowledgment of difference is crucial to Philip's sense of selfhood. Now placed in the context of a multiethnic and multiracial history, Philip Hutton's biracial hybridity becomes a unique space which, instead of isolating him from his surroundings, undoes the dichotomies that mark his society: British-Chinese, colonizer-colonized, victim-perpetrator. This hybridity becomes an alternative space from which he can forge connections-not only with the others of the community but also with the memories of the individual and the communal past.

This hybrid selfhood shapes Philip's actions during the War. According to a prophecy made to the grandfather, Philip - the "child of mingled blood" (Tan, The Gift of Rain 137) - would betray his family and bring destruction to his country. Philip's intimate friendship with Endo leads to the fulfillment of the prophecy, but not before he realizes that Endo, his intimate friend and teacher, had betrayed him first by exploiting his youthful naiveté and loneliness to get important information about Penang's strategic sites and defenses. The gathered intelligence paves the way for Japan's attack and the takeover of Penang.

To this narrative of brutal colonization and psychic trauma inflicted on the colonized subject, Tan adds another dimension by the revelation that Philip and Endo are romantic partners caught in a seemingly endless cycle of reincarnation. In an episode in the novel, Philip, in a trance-like state, witnesses the beheading of his past self by Endo's past self. After the trance, Philip feels his neck "hurting from remembered pain." This transcendental dimension seems to lift the story from the plane of historical and political reality. For Goh Cheng Fai, the reincarnation 
subplot is a literal reenactment of Philip's trauma where the repetitions of the karmic cycle substitute for the involuntary flashbacks of the traumatic events in the victim's mind. Challenging the notion of a transcendental relationship, Weihsin Gui argues that the story of an eternal romance through the cycles of incarnations is an evidence of Tan's use of exoticism to critique the postcolonial marketplace and its desire for the Orientalist narratives from Asia. David Lim, on the other hand, undoes the transcendental aspect of this relationship by situating it in the context of history and power in the seventeenth-century Japan. Lim reads various aspects of Philip and Endo's relationship_its pedagogic impulse, the homoerotic kernel, and Philip's naiveté-in the context of the hegemonic ties of the Japanese practice of Shudo: a "way of loving youths, an erotic path that younger males traveled only in their capacity as sexual objects" ("Agency and the Pedagogy of Japanese Colonialism" 240).

In the text, Philip's refusal to submit to the cyclical repetition of history relocates the entire drama in the socio-political realm instead of reifying it to a transcendental plane. Though Endo submits to this repetition of the historical pattern by sacrificing Philip for duty, Philip, with his multifarious connections and shifting set of loyalties, undermines the absolute submission to history or to the colonial authority. During the war years, Philip uses the aikido training and all that he had learned from Endo to undermine the authority of the Japanese forces. His anguish regarding the safety of his family and of Penang compels Philip to become a spy, leaking the secrets of his Japanese masters to the resistance groups which include his grandfather, his friends, and others of the Chinese community in Malaya. His role as a double agent reenacts the multidirectional nature of his subjectivity. On the one hand, it is evident that Philip escaped complete indoctrination by the Japanese propaganda machinery and cast his lot with his family and with Penang. Yet he believes that what he learned from Endo is his greatest legacy (Tan, The Gift of Rain 438). Thus, Philip's subjective orientation, shaped by the racial and ethnic heritage of his Chinese ancestry, his affinity towards the Japanese culture, and his love for his English family, remains multidirectional. He eventually grows out of his childhood solipsism to establish a connection with his father and forge close friendships with others. Unlike his aikido master Endo, who could be defined in terms of his unswerving devotion to the Japanese empire, Philip is able to forge relationships that are beyond the boundaries of nationalities and ethnicities. From experiences and memories that are historically and culturally specific grow connections that are transcultural and transhistorical. 


\section{MULTIDIRECTIONAL MEMORIES}

Instead of historical continuity through family and lineage, Tan's novel is about shared memory, "memory that may have been initiated by individuals but that has been mediated through networks of communication, institutions of the state and the social groupings of civil society" (Rothberg, Multidirectional Memories 15). As a framed narrative, Tan's novel adds multiple layers to the relationship between the bearers of memory or the victims of trauma and their listeners. Philip enacts the role of a listener to his grandfather's traumatic memories of the disintegration of the Chinese royal family and his forced journey to Malaya. As discussed earlier, the story has a marked political and social relevance. The grandfather's memories provide Philip with a sense of belonging and connectedness that he had been missing until then. Beyond the individual, the memories not only enable the Chinese community in Malaya to create close bonds in exile, they also keep them attached to the homeland. As the news of the Japanese atrocities in China reaches Malaya, the community becomes active in providing aid, something for which they suffer when the Japanese come to Malaya.

Intertwined with Philip's story is Michiko's account of her short-lived affair with Endo and her losses during the war. She describes the arrival of Endo's letter as an intrusion in grief as she mourned the death of her husband of fifty years. It compels her to take the journey to meet Philip in order to learn about Endo's life in Malaya. While Michiko fulfills her end of the implicit contract by bearing witness to Philip's story, she also tells about the death of her family and her impending death due to radiation poisoning caused by the atomic bomb dropped near her village. Towards the end of the narrative, as they visit Endo's grave, Philip is not only aware of his own past; he sees "the memory of her love for Endo-San" (Tan, The Gift of Rain 439).

Such multidirectionality of memory where the narrativization of trauma encourages the articulation of other traumatic experiences posits "a collective memory as partially disengaged from exclusive versions of cultural identity and acknowledges how remembrance both cuts across and binds together diverse spatial, temporal and cultural sites" (Rothberg, "From Gaza to Warsaw" 11). Multidirectional memory implies the juxtaposition of two or more disturbing memories that work dialogically to bring together different histories of suffering and is based on an "ethics of comparison that can distinguish politically productive forms of memory from those that lead to competition, appropriation and trivialization" (Rothberg, "From Gaza to Warsaw" 18). Instead of projecting Philip and Michiko as Malaysian and Japanese subjects, thereby underlining the past hostilities or comparing the losses suffered by their respective countries during the war, Tan's novel opens a discursive space for multidirectional memory that avoids the markers of nationality and promotes awareness across the boundaries. As

Kritika Kultura 33/34 (2019/2020): 193-197

(C) Ateneo de Manila University

<http://journals.ateneo.edu/ojs/kk/> 
they near the end of the narrative, Michiko wonders if a person requires anything besides memories. Philip's answer is unequivocal.

I examined her words carefully, and the answer came slowly but without any equivocation. 'Someone to share those memories with', I said finally, surprising myself. I had never actually made the decision not to discuss my activities during the Japanese Occupation (Tan, The Gift of Rain 411).

As he ends his account, Philip is aware of the deep sense of solidarity with Michiko that "she alone, of all the people in the world, would understand" (Tan, The Gift of Rain 431). The juxtaposition of colonial trauma with the memories of a war survivor contextualizes trauma in the dialogic space between histories, memories, and narratives.

\section{LIVING WITH THE PAST}

Despite Philip's belief that few would understand him and his decisions, his traumatic experiences largely overlap with his postcolonial condition - the collective suffering of the colonized populace that is a symptom of socio-historical power formations in a colonized world. Philip's alienation due to his mixed ancestry, the intensity of his relationship with Endo and the subsequent betrayal, the psychic trauma-all these are the manifestations of the colonial power equations.

Caruth, in her discussion on trauma, evokes a shift from objective representation to an emphasis on individual and collective memories "where we begin to recognize the possibility of a history which is no longer straightforwardly referential (that is, no longer based on simple models of experience and reference)" (Unclaimed Experience 182). Philip's narrative navigates through similar slippages between the past and the present as the individual memories and trauma become a part of transhistorical and transnational network of memory. In the process, Tan's novel becomes an exploration of the non-linear trajectories and complex temporalities where past and present are reflected upon and re-calibrated.

Instead of a narrative predicated on one way relationship between a victim and a listener, The Gift of Rain creates a dialogic space where Philip's experiences during the War are interspersed by Michiko's memories, the story of his Chinese grandfather, and the experiences of his father, an Englishman in Malaya. Such sharing of memories does not aim at suturing the split subjectivities or healing the trauma. Several readers and critics have focused on the healing potential of Philip's narrative, its ability to excise the pain by mourning for Endo and thereby 
overcoming the fixation in the past. Leon and Koh insist that with the recovery of his full name, Philip begins to claim his painful past and the process of healing can begin: "When I heard my name - my complete, dear name, given to me by both my parents and by my grandfather [...] I experienced a feeling of integration and fulfillment that had eluded me all of my life" (Tan, The Gift of Rain 443). Yet the name, Philip Arminius Khoo-Hutton, is a signifier of Philip's postcolonial identity, split and shaped by the colonial experience. His attempts to let go of Endo's memories are marked by ambiguity. At a function of Penang Historical Society, he is still searching for Endo in the old photographs (Tan, The Gift of Rain 442). In the end, Philip keenly looks forward to moving on to live on Endo's island for the rest of his days (Tan, The Gift of Rain 443). The novel ends with the belief that "we can do nothing else but live our remembered desires and memories of our hearts" (Tan, The Gift of Rain 444). Thus sharing the story of the past with Michiko does not entail "letting go" of the past. The act of storytelling has enabled Philip to forge connections with the past. The narrative ends with a suggestion of a critical engagement with history or living with the past in the present. Instead of recovery, the postcolonial condition entails survival with the traumatic memories. It is only by sharing that one can reach beyond the preoccupation with individual pain and built connections. 


\section{Works Cited}

Augustin, James Frederick. Bygone Eurasia: The Life-story of the Eurasians of Malaya. Rajiv Printers, 1970.

Caruth, Cathy. Trauma: Explorations in Memory. John Hopkins UP, 1995.

-.. Unclaimed Experience: Trauma, Narrative, and History. John Hopkins UP, 1996.

Craps, Stef. Postcolonial Witnessing: Trauma Out of Bounds. Palgrave MacMillan, 2012.

--. "Wor(l)ds of Grief: Traumatic Memory and Literary Witnessing in Cross-cultural Perspective." Textual Practice, vol. 24, no. 1, 2010, pp. 51-68.

Craps, Stef, and Gert Buelens. Introduction. Postcolonial Trauma Novels. Studies in the Novel, vol. 4., no. 1, 2008, pp. 1-2.

Dalley, Hamish. The Postcolonial Historical Novel: Realism, Allegory, and the Representation of Contested Pasts. Palgrave MacMillan, 2014.

Durrant, Sam. Postcolonial Narrative and the Work of Mourning: J.M. Coetzee, Wilson Harris, and Toni Morrison. State U of New York P, 2004.

Erll, Astrid. “Travelling Memory." Transcultural Memory, edited by Rick Cronshaw, Parallax, special issue, vol. 17, no. 4, 2011, pp. 4-18.

Felman, Shoshana, and Dori Laub. Testimony: Crises of Witnessing in Literature, Psychoanalysis, and History. Routledge, 1992.

Feindt, Gregor, Félix Krawatzek, Daniela Mehler, Friedemann Pestel, and Rieke Trimçev.

"Entangled Memory: Toward a Third Wave in Memory Studies." History and Theory, vol. 53, 2014, pp. 24-44.

Goh Cheng Fai. "Hurting from the Remembered Pain: Reincarnation, Memory and Trauma in Tan Twan Eng's The Gift of Rain." Third Global Conference, Trauma Theory and Practice (TTP3), 19-21 Mar. 2013, Lisbon, Paper Presentation. Academia.edu - Share research. https://www.academia.edu/7093632/Hurting_from_Remembered_ Pain_Reincarnation_Memory_and_Trauma_in_Tan_Twan_Engs_The_Gift_of_Rain. Accessed 25 Sept. 2017.

Gui, Weihsin. National Consciousness and Literary Cosmopolitics: Postcolonial Literature in a Global Moment. Ohio State UP, 2013.

Holden, Philip. "Global Malaysian Novels: Prospects and Possibilities." Kajian Malaysia, vol. 30, no. 1, 2012, pp. 47-59.

LaCapra, Dominick. “Trauma, Absence, Loss." Critical Inquiry, vol. 25, no. 4, 1999, pp. 696-727.

--. Writing History, Writing Trauma. John Hopkins UP, 2013.

Leon, Carol, and Gladys Koh. "Retrieving Lost Histories: Spaces of Healing, Spaces of Liberation." Asiatic, vol. 8, no. 2, 2014, pp. 110-124.

Lim, David. "Agency and the Pedagogy of Japanese Colonialism in Tan Twan Eng's The Gift of Rain." Critique, vol. 52, no. 2, 2011, pp. 233-47.

--. Introduction. Overcoming the Passion for Race in Malaysia Culture Studies, edited by David Lim, Brill, 2008, pp. 1-12. 
Lloyd, David. "Colonial Trauma/Postcolonial Recovery." Interventions: International Journal of Postcolonial Studies, vol. 2, no. 2, 2011, pp. 212-228.

Poon, A. "Transcultural Aesthetics and Postcolonial Memory: the Practices and Politics of Remembering in Tan Twan Eng's The Garden of Evening Mists." Cambridge Journal of Postcolonial Literary Inquiry, vol. 3, no. 2, 2016, pp. 1-17.

Rigney, Ann. "Portable Monuments: Literature, Cultural Memory, and the Case of Jeanie Deans." Poetics Today, vol. 25, no. 2. 2004, pp. 361-396.

Root, Maria. "Reconstructing the Impact of Trauma on Personality." Personality and Psychopathology: Feminist Reappraisals, edited by Laura S. Brown and Mary Ballou, Guilford, 1992, pp. 229-265.

Rothberg, Michael. "From Gaza to Warsaw: Mapping Multidirectional Memory." Criticism, vol. 53, 2011, pp. 523-48.

-.. Multidirectional Memory: Remembering the Holocaust in the Age of Decolonization. Stanford UP, 2009.

-.. "Preface: Beyond Tancred and Clorinda: Trauma Studies for Implicated Subjects." The Future of Trauma Theory: Contemporary Literary and Cultural Studies, edited by Gert Buelens, Samuel Durrant, and Robert Eaglestone, Routledge, 2014, pp xi-xviii.

Tan Twan Eng. "I Have No Alternative but to Write in English." Interview with Tan Twan Eng, By Stephen McEwen, The Spectator, 20 May 2013, https://blogs.spectator. co.uk/2013/o5/tan-twan-eng-interview-i-have-no-alternative-but-to-write-in-english/. Accessed 25 Sept. 2017.

--. The Garden of Evening Mist. Myrmidon, 2012.

-.. The Gift of Rain. Myrmidon, 2007.

Visser, Irene. "Decolonizing Trauma Theory: Retrospect and Prospects." Humanities, vol. 4, no. 2, 2015, pp. 250-265. DOI: 10.339o/h4020250. 